\title{
Flexural Properties of Bamboo-Log Composite Beam
}

\author{
Qiang Chen ${ }^{1,2}$, Jianke Lang ${ }^{1}$ and Jiejun Wang ${ }^{1, *}$ \\ ${ }^{1}$ School of Civil Engineering, Central South University of Forestry and Technology, Changsha 410004, China \\ ${ }^{2}$ School of Civil Engineering, Hunan City University, Yiyang 413000, China
}

Received 3 December 2017; Accepted 26 May 2018

\begin{abstract}
Timber is a renewable, environmentally friendly construction material. Moreover, the span and flexural capacity of traditional timber structures are sensitive to many material properties. To improve the poor bearing capacity of timber structures, a bamboo-log composite beam was constructed by using the log as the skeleton and connecting glue-laminated bamboo with epoxy resin adhesive. A three-point stress-bending test was conducted by using three log beams and three bamboo-log composite beams with consistent structural size and features. The failure mode, ultimate flexural capacity, flexural rigidity, and strain changes of these beams were studied. Experimental results demonstrate that the $\log$ beam and bamboo-log composite beam indicate brittle failures and natural defects of two raw materials that can significantly influence flexural capacity. Strain of the midspan section along the height continues to conform to the plane cross-section assumption, thereby indicating that bamboo and log can cooperate. The flexural capacity of the bamboo-log composite beam increases by $17.5 \%-75.6 \%$ and flexural rigidity increases by $43.9 \%-49.4 \%$ compares with those of the log beam. Furthermore, the midspan ultimate deflection increases by $-1.3 \%-58.2 \%$. Results reveal that bamboo in the bamboo-log composite beam fully develops tensile properties, thereby resulting in significant improvements in flexural rigidity and flexural capacity. Finally, a calculation formula of the flexural capacity of the bamboo-log composite beam was proposed. The theoretical results and experimental results were compared, and the mean error is lower than $10 \%$. This study provides experimental and theoretical references to bamboo-log composite beam design and the application of bamboolog composite beams in timber structures.
\end{abstract}

Keywords: Glue-laminated bamboo, Log, Composite beam, Flexural property

\section{Introduction}

People's consciousness on nature, health, and environmental protection is increasing gradually as economic development progresses. Timber structures are increasingly used for their energy-saving, emission reduction, and environmentfriendly construction characteristics. However, engineering timbers (e.g., Pinaceae and cedar) need dozens and even hundreds of years to grow. Artificial fast-growing woods have short growth cycles but indicate loose woodiness and poorer design strength value and elasticity modulus than the engineering requirements. Moreover, timber consumption is significantly higher than the yield [1], thereby resulting in the high cost. Under this circumstance, the composite timber structure has been developed, which not only solves the low bearing capacity and poor fire and corrosion resistance of single timber structures but also further decreases the section size and increases timber utilization at a low cost. The process results in a light and beautiful overall structure. Thus, the composite time structure is crucial to the safety and reliability of timber structural systems.

Compared with the traditional simple timber structure, the composite timber structure is diversified. Existing studies mainly focus on steel-timber composite, timbermixed composite, and carbon fiber reinforcement timber structures, as well as laminated wood and laminated bamboo structures. Flexural property, shearing performance, and

*E-mail address: wangijejun2011@126.com

ISSN: $1791-2377$ @ 2018 Eastern Macedonia and Thrace Institute of Technology. All rights reserved. doi:10.25103/jestr.113.14 connection performance of these structures have been explored via numerous experiments[2-4]. With high bearing capacity and certain ductility, these common composite structures can be used in large-span bridges and high-rise buildings. However, in practical engineering, the energy consumption of steel materials and concrete in the full life circle of buildings is far higher than that of timber. Carbon fiber claims too high a cost. Laminated wood and laminated bamboo indicate high requirements on manufacturing technology. Furthermore, the diversified binders and nonenvironmental-friendly raw materials restrict the promotion of composite timber structures.

To offset the disadvantages of these composite structures, the composite timber structure needs to be improved. Given their high endwise tensile strength and higher strength-toweight ratio than steel materials, bamboo materials can be used to replace steel materials to improve the mechanical properties of timber structures. In this study, a bamboo-log composite beam was proposed, and theoretical analysis and experimental study on the flexural property of the proposed composite beam were conducted.

\section{State of the art}

The composite timber structure has diversified forms. Recently, physical and mechanical properties of the structure have been explored by scholars at home and abroad. In timber-mixed composite structures, $\mathrm{Hu}$ et al.[5] tested the flexural properties of one complete shear-connected timber- 
concrete composite beam and three shear-connected timberconcrete composite beams under static loads. They concluded that the mechanical behavior of a composite beam is slightly influenced when the connector interval exceeds four times the diameter. On this basis, Chen et al.[6] reinforced laminated timber-concrete composite beam by using carbon fiber composite material, and showed significant reinforcement effect. Szumigala et al.[7] carried out numerical analysis on the bearing capacity and rigidity of timber-concrete composite beam. Balogh et al.[8] studied the connection performance of timber-concrete composite beam with notch connections under cyclic loading and longterm loading. Subsequently, Lorenzo Boccadoro et al.[9] established a notch connection analysis model for timberconcrete composite plate. These studies all used timber materials as the main bearing components. Timber sustained the loads of the upper concrete except for the dead load. At present, timber structures are weaker than concrete structures. Moreover, guaranteeing the stability of timemixed composite structures under long-term loads is difficult.

In steel-timber composite structures, Chen et al. [10] tested the flexural properties of nine steel-timber composite $\mathrm{H}$-shaped beams, and found good overall work performances of the H-shaped steel and wood plate. In the loading process, the lower-flange timber suffered midspan breakage, and the bearing capacity of specimens was proportional to the wood plate thickness, thickness, and width of the steel beam flange, as well as web height. Furthermore, Chen et al. proposed a simple calculation formula for the flexural capacity of steeltimber composite H-shaped beams. Sun et al. [11] conducted nonlinear analysis on the flexural performance of nine steeltimber composite beams by using ABAQUS and conducted a systematic study on model definition, modeling, and spring unit of the two materials. Analysis results demonstrated that $\mathrm{H}$-shaped steel web height is the primary influencing factor of flexural capacity and web thickness is the least important factor. Hindman et al.[12] reinforced the woody I-type joist by using two types of cold-forming sectional steel stiffeners, and indicated that the double-web stiffener achieved the most outstanding effect. Soriano et al. [13] used rebar with two different ratios to reinforce laminated timber to reduce the inherent variability of timber and increase the ultimate bearing capacity of beams. Loss et al.[14] proposed a new multi-functional building composed of timber and steel materials and tested the connecting pieces, and indicated that this structural system has high potential. Li et al.[15] evaluated the comprehensive seismic resistance of multilayer steel-timber composite structures. In these studies, steel materials were used for the skeleton and timber was used as the facing material; such use significantly increased bearing capacity. This structure can be applied to houses with light steel structures. However, the steel utilization was high, and environmental protection quality and resource utilization should be further improved.

Given the development of new technologies, a new processed carbon fiber-reinforced plastics (CFRP), an ultrahigh performance reinforced carbon material, is increasingly used in architecture. Meanwhile, laminated wood and laminated bamboo structures have elicited considerable scholarly attention. Khelifa et al.[16] conducted bending test and finite element analysis of CFRP-reinforced timber beams with finger joint and simulated the failure mode of the beam. The numerical analysis results were close to test results. Xiong et al.[17] conducted stressed bending experiments at two points of 42 timber composite beams with different sections. Estévez-Cimadevila et al.[18] tested the flexural performance of 16 orthogonal laminated wood species by using a type of web timber material and bonded pre-stressed tendon as the test parameters. Xiao et al.[19] studied laminated bamboo plates with three different carbon layouts and tested shearing strength under different loading conditions. The designed values and strengths of laminated bamboo structures were derived from the test results. These studies were based on modern binding technology and processing technology. These approaches introduced challenges to the manufacturing level of factories and increased intangible manufacturing cost. Moreover, the binder consumption increased. Therefore, developing environmental-friendly binders based on satisfying bonding strength is necessary.

China possesses rich bamboo resources. Bamboo grows quickly and can grow in 3-5 years. Moreover, bamboo possesses reproducible characteristics and is known as a green building material. Chen et al.[20-21] prepared a laminated bamboo-timber $\mathrm{H}$-shaped beam by using the oriented strand board (OSB) and bamboo laminated wood. They conducted flexural performance and static load tests by using shear span ratio and stiffening ribs as test parameters. Results demonstrated that the shear span ratio is positively related to the reduction rate of the ultimate bearing capacity, and that stiffening ribs can significantly increase the ultimate bearing capacity of beams. Paniagua et al.[22] conducted flexural performance tests on $\mathrm{H}$-shaped beams composed of glue-laminated bamboo and laminated plates. The tested flexural strength and shear strength all met the standards. These studies explored bamboo-timber composite structures; however, they only focused on the mechanical properties of $\mathrm{H}$-shaped beams. Further studies on other sectional forms should be accomplished.

To overcome the disadvantages of existing studies, a bamboo-log composite beam was proposed. In this structure, the glue-laminated bamboo is bonded at the bottom of timber beam by a binder, which can reinforce the tensile properties of beams and increase the flexural capacity of the whole structure. On this basis, three log beams and three bamboo-log composite beams were chosen for the contrast experiments of stressed performances at three points, in order to verify the collaborative deformation ability of gluelaminated bamboo and log beams. Variations in failure mode, deflection, bearing capacity, flexural rigidity, and strain of six specimens during the loading process were tested, and provided experimental references for applications of this new composite beam.

The remainder of this study is organized as follows: Section 3 elaborates the flexural test of $\log$ beams and bamboo-log composite beams. Section 4 analyzes the failure phenomenon, deflection, bearing capacity, and rigidity using test results, and proposes a theoretical calculation formula for deriving the flexural capacity of bamboo-log composite beams. Theoretical calculation results were compared with experimental results. Furthermore, the influences of gluelaminated bamboo on mechanical properties of $\log$ beams were discussed. Conclusions are summarized in Section 5.

\section{Methodology}

\subsection{Specimen design}

In the experiment, three $90 \mathrm{~mm} \times 135 \mathrm{~mm} \times 2000 \mathrm{~mm} \log$ beams and three bamboo-log composite beams (A1-A3 and B1-B3) were designed. To study the effects of bamboo on the mechanical properties of composite beams, a $5 \mathrm{~mm}$-thick 
bamboo layer was pasted to the lower surface of the $\log$ beam. At two ends of specimens, $70 \mathrm{~mm}$ was reserved, and the actual span $(L)$ between the supports was $1860 \mathrm{~mm}$. Specific specimen parameters are listed in Table 1.

Table 1. Details of test specimens

\begin{tabular}{c|c|c|c|c}
\hline Specimen No. & $\begin{array}{c}b \times h \\
/(\mathbf{m} \mathbf{m} \times \mathbf{m m})\end{array}$ & $\begin{array}{c}L \\
/(\mathbf{m m})\end{array}$ & Bamboo plate & Knag \\
\hline A1 & $90 \times 135$ & 1860 & No & Evident knag in the tensile region \\
\hline A2 & $90 \times 135$ & 1860 & No knag in the tensile region & Evident knag in the tensile region \\
\hline A3 & $90 \times 135$ & 1860 & No & Evident knag in the tensile region \\
\hline B1 & $90 \times 135$ & 1860 & Yes & No knag in the tensile region \\
\hline B2 & $90 \times 135$ & 1860 & Yes & No knag in the tensile region \\
\hline B3 & $90 \times 135$ & 1860 & Yes & \\
\hline
\end{tabular}

Pinus sylvestris was chosen as the test material. The density, moisture content, and elastic modulus were 432 $\mathrm{kg} / \mathrm{m}^{3}, 13.2 \%$, and $7254 \mathrm{MPa}$, respectively. The bamboo plate used the laminated bamboo produced by Hunan Yiyang Taohuajiang Bamboo Co., Ltd. The plate processed from 6-year-old moso bamboo $(5 \mathrm{~mm} \times 90 \mathrm{~mm} \times 2000 \mathrm{~mm})$. Density, moisture content, and elastic modulus were tested as $820 \mathrm{~kg} / \mathrm{m}^{3}, 10.7 \%$, and $10150 \mathrm{MPa}$, respectively.

\subsection{Selection of bamboo-timber binder}

To choose the appropriate bamboo-log binder, adhesive properties of white emulsoid, special wood glue, nail-free glue, and $\mathrm{AB}$ epoxy glue, which are common commercial binders, were tested. Shearing experiments of 38 bambootimber connectors were conducted. The bamboo-timber composite structure was composed of $25 \mathrm{~mm} \times 25 \mathrm{~mm} \times 100 \mathrm{~mm}$ wood beam and $3 \mathrm{~mm} \times 25 \mathrm{~mm} \times 100 \mathrm{~mm}$ bamboo plate. The structural size is shown in Fig.1.

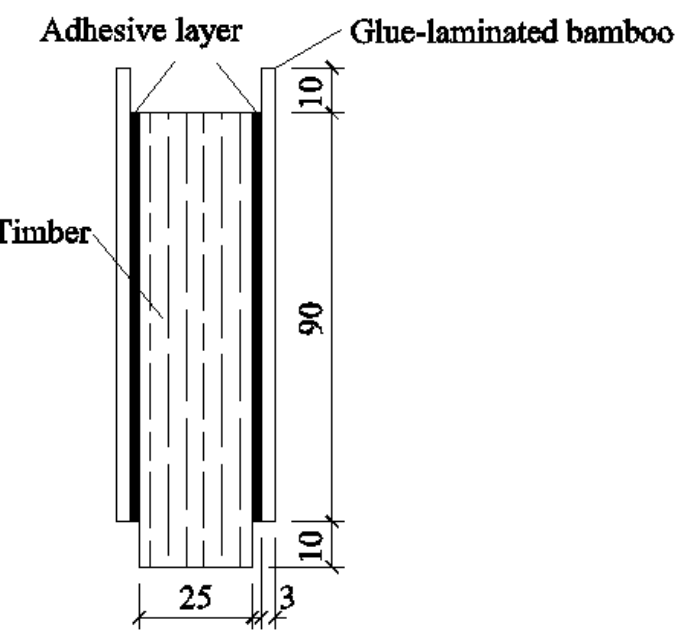

Fig. 1. Bamboo-timber connection test specimens

Shearing tests of specimens were conducted on an assembly load sensor and the counter-force frame of jack. Test process and failure mode of specimens are shown in Figs 2 and 3.

The shearing experimental results of bamboo-timber connector indicated that the average failure loads of 38 specimens using white emulsoid, special wood glue, nailfree glue, and $\mathrm{AB}$ epoxy glue were 4.02, 8.18, 7.24, and $10.01 \mathrm{kN}$, respectively. The dispersion degree of the $A B$ epoxy glue was the lowest, thus indicating that the $A B$ epoxy glue is feasible for preparing the bamboo-log composite beam.
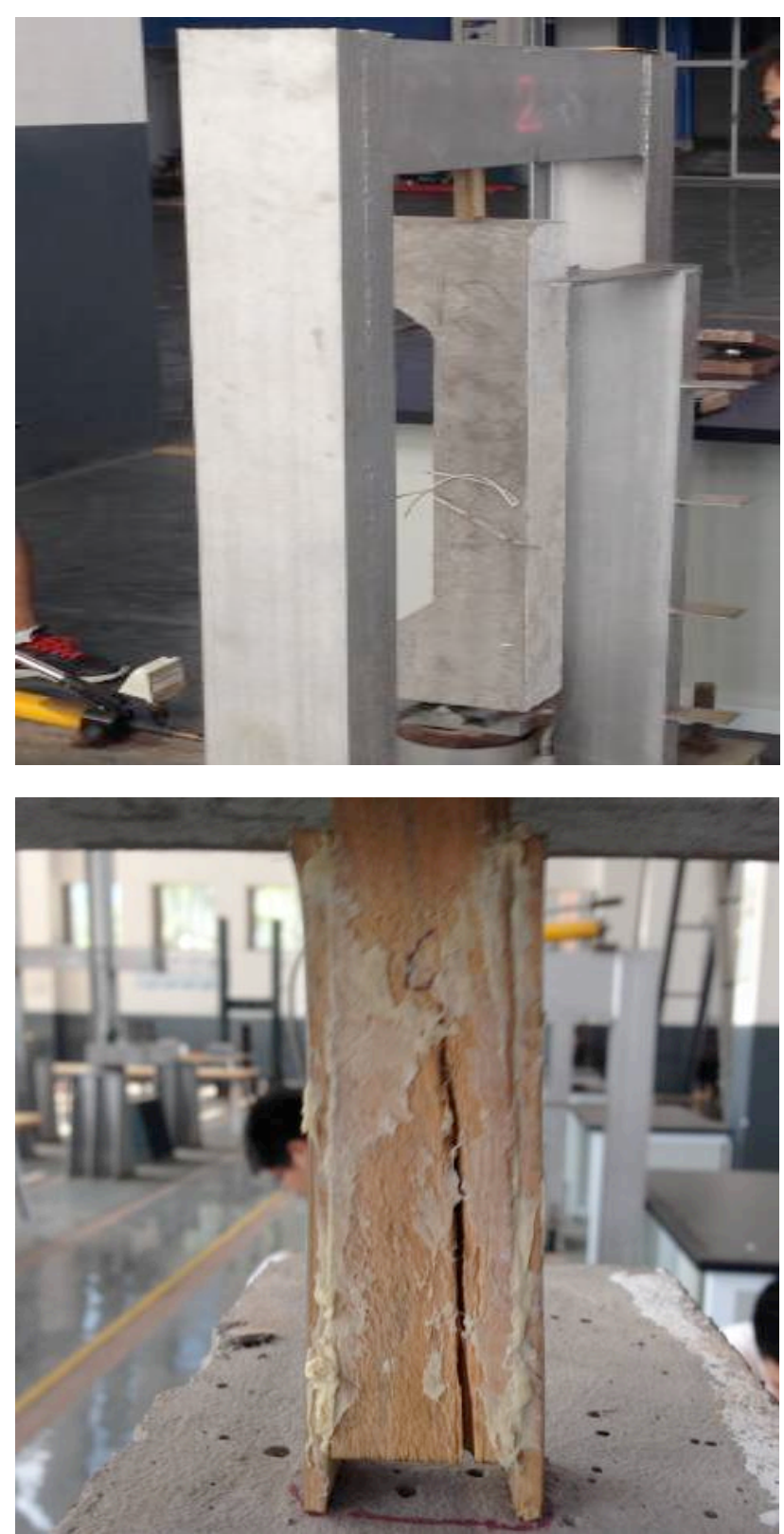

Fig. 2. Shear test of bamboo-timber connection specimens

In the experiment, $\mathrm{AB}$ epoxy glue was used. The steelsteel tensile strength and the steel-steel shearing strength exceeded 40 and $18 \mathrm{MPa}$, respectively. The preliminary curing and complete curing times were 3 and $24 \mathrm{~h}$, respectively. First, the interface between the timber beam and bamboo plate was flattened and cleaned by alcohol or acetone. Double-face coating was adopted. After compression, glue solution was extruded partially from the interface edges. Forming a glue line after curing of the extruded glue solution was appropriate. Next, a heavy object 
was laid on the structure statically and was temporarily fixed by a wooden clamp to prevent relative slippage between timber beam and bamboo plate. Finally, specimens were pressed at approximately about $20^{\circ} \mathrm{C}$ for $48 \mathrm{~h}$ and maintained under dry conditions for $5 \mathrm{~d}$.

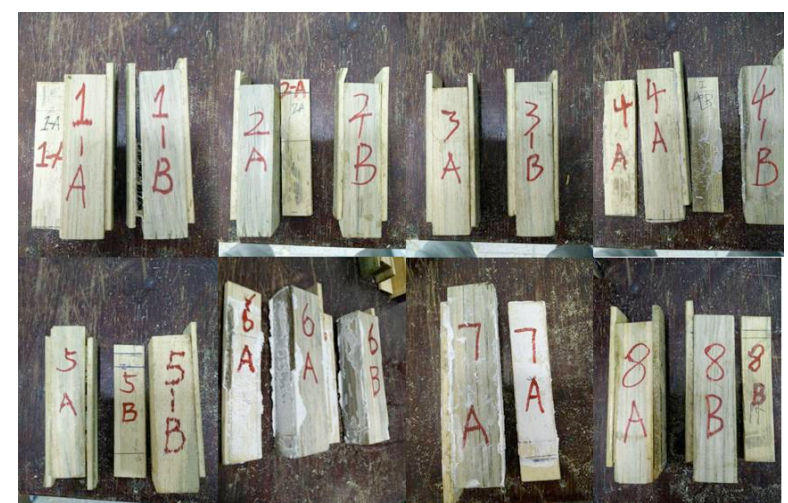

Fig. 3. Failure mode of bamboo-timber connection test specimens
3.3 Loading device and arrangement of testing points Manufacturing, processing, and relevant tests of beams were conducted in the Structural Laboratory of National Experimental Teaching Demonstration Center, Civil Engineering of Hunan City University. To record vertical displacement and strain of specimens in the loading process, five displacement meters (\#7-11) were set atop two ends, beneath the loading point and midspan position. Five strain gauges (\#14-18) were set along the height at two sides of the midspan section. Rest strain gauges were set at top and bottom of $\mathrm{L} / 4, \mathrm{~L} / 2$, and $3 \mathrm{~L} / 4$ (\#1, 2, 3, 4, 5, 6, 12, 13, 19, 20, 21, and 22). A total of 22 strain gauges were applied. Data were collected by the DH3818 static strain tester and vertical loads were delivered to specimens via the distribution beam that connected to the load sensor. Three-point loading was adopted. Specimens were pre-stressed prior to formal loading and each level of loading was $5 \mathrm{~min}$. The loading device in the experiment is shown in Fig.4.

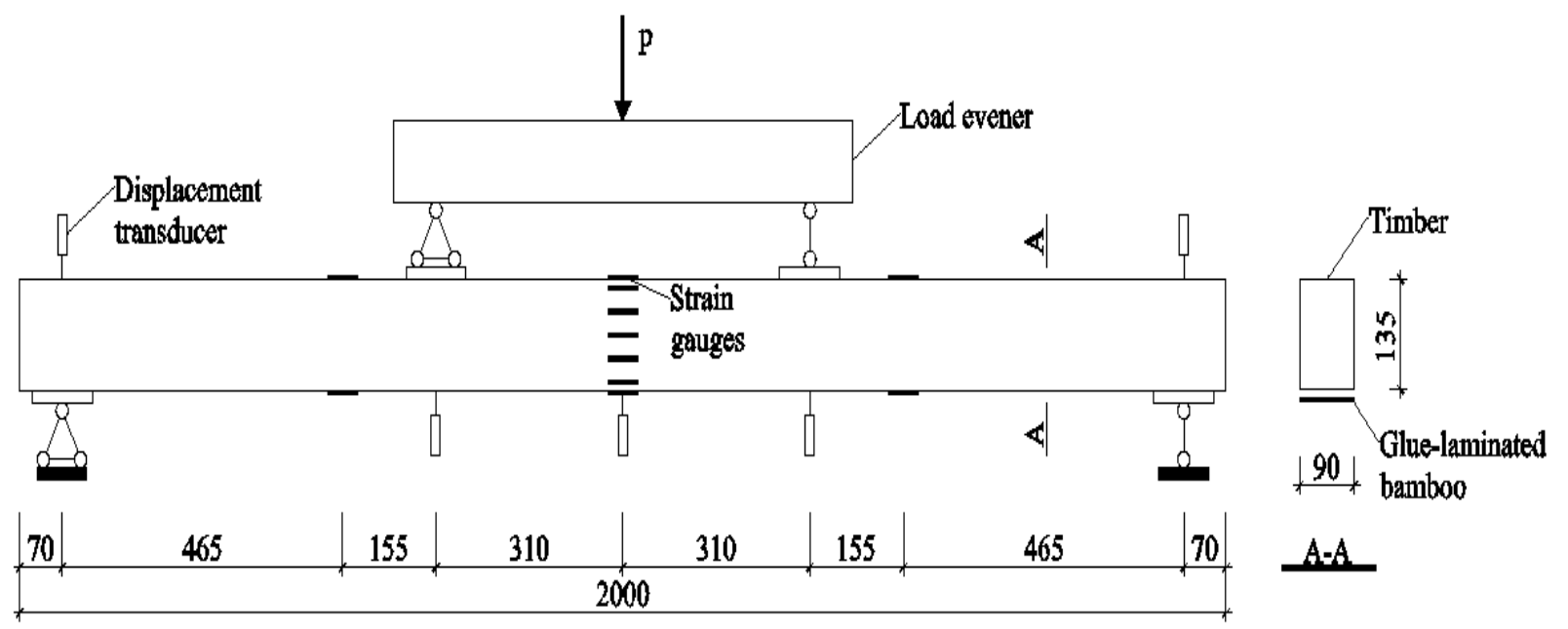

Fig. 4. Test setup

\section{Result Analysis and Discussion}

\subsection{Experimental phenomena and main outcomes}

\subsubsection{Test failure mode}

Based on the flexural performance test of three log beams and three bamboo-log composite beams in Section 3.3, the failure modes of six specimens were analyzed. A1-A3 were $\log$ beams. When the load was increased to $11 \mathrm{kN}, \mathrm{A} 1$ generated a "squeak," and a knag in the tensile region cracked along the grain direction. When the load was increased to $18 \mathrm{kN}$, the crack further was extended along the $45^{\circ}$ direction. As the load was further increased to $24 \mathrm{kN}$, the transverse striation was stretched, thereby causing longitudinal splitting failure. When the load reached $40 \mathrm{kN}$, A2 emitted a "bang" sound and the midspan bottom underwent tensile failure. At $22 \mathrm{kN}, \mathrm{A} 3$ underwent cracks at the knags in the tensile region. At $28 \mathrm{kN}$, cracks at the knag of the specimen bottom expanded along the $45^{\circ}$ direction. Splitting failure occurred when the load was increased to $34 \mathrm{kN}$, and showed no evident indicators. All specimens suddenly failed.

B1-B3 were bamboo-log composite beams. B1 generated a "squeak" at $32 \mathrm{kN}$, and the compressive zone of the loading point cracked. At $44 \mathrm{kN}$, the tensile side of the simple bending zone broke, accompanied by a loud sound.
The specimen underwent brittle failure. B2 was cracked in the compressive zone at the midspan top when the load was increased to $33 \mathrm{kN}$. Cracks developed into shearing failure along the grain when the load was increased to $50 \mathrm{kN}$. When the load reached $46 \mathrm{kN}, \mathrm{B} 3$ cracked in the compressive zone at the midspan top, accompanied with a "squeak." When the load was increased to $56 \mathrm{kN}$, the bamboo plate broke at the midspan, and specimens failed upon tensile stress, without obvious indicators. All specimens suffered failure quickly.

Typical failure modes of specimens are shown in Figs. 5 and 6.

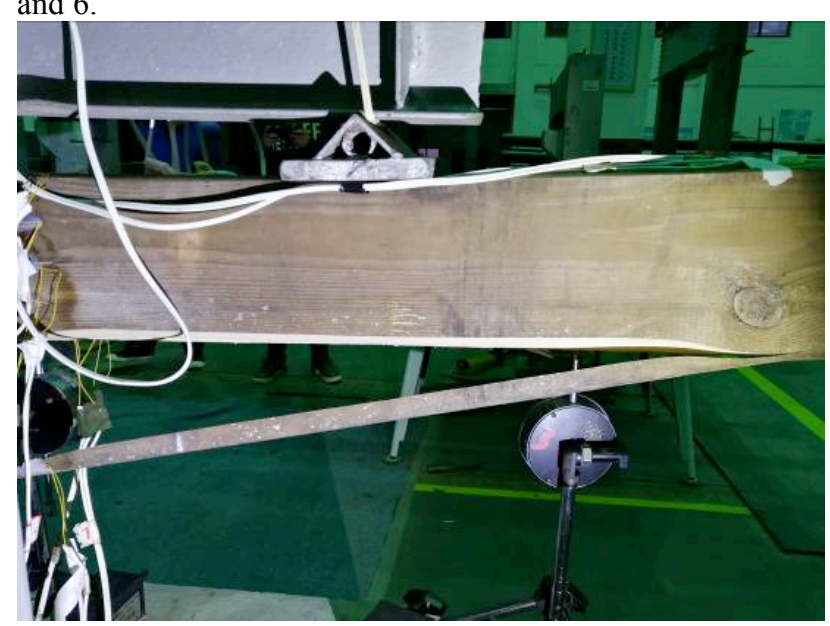

(a) Cracking at beam bottom 


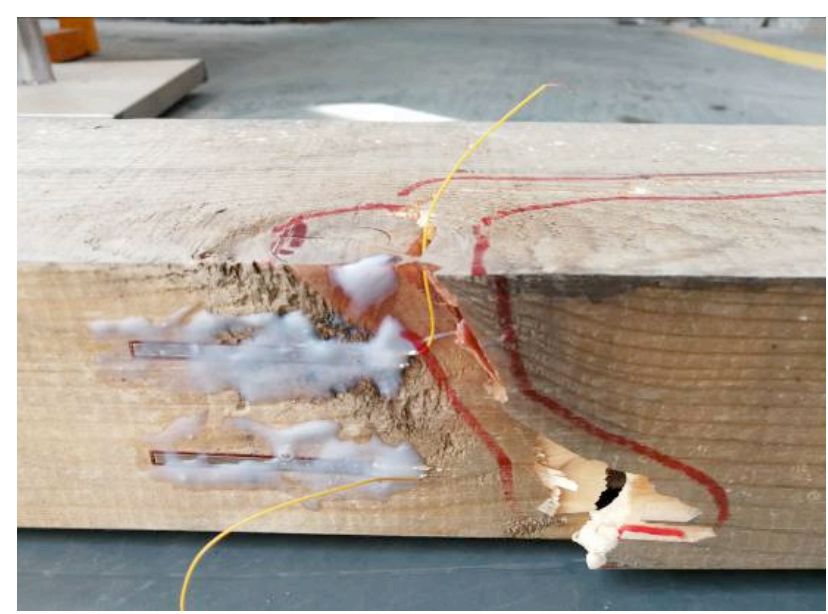

(b) Splitting failure at beam bottom

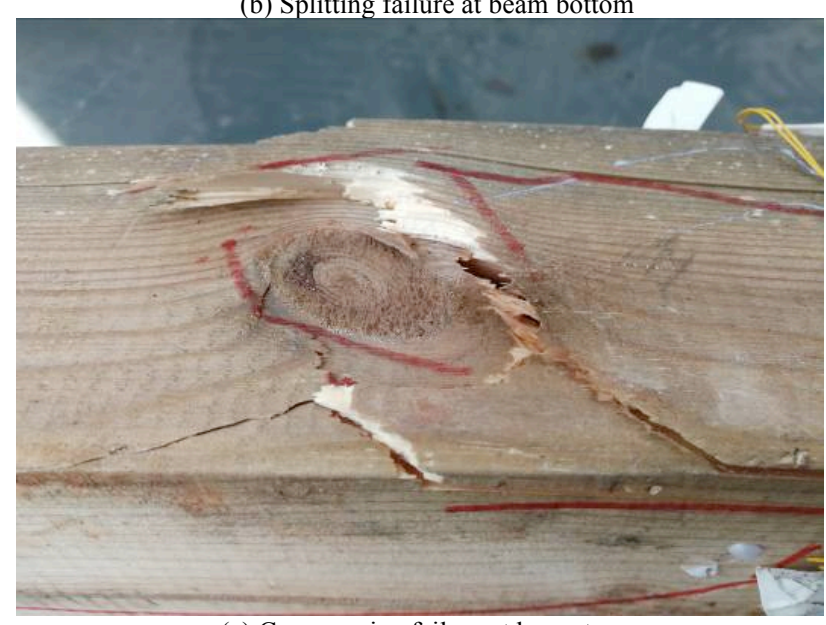

(c) Compressive failure at beam top

Fig. 5. Typical failure modes of group A

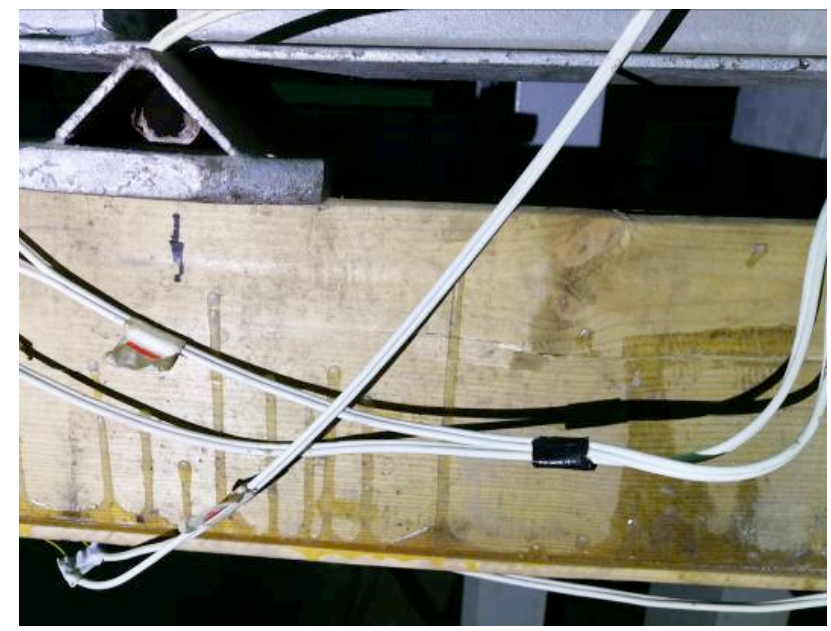

(a) Upheaval of compressive zone at the beam side

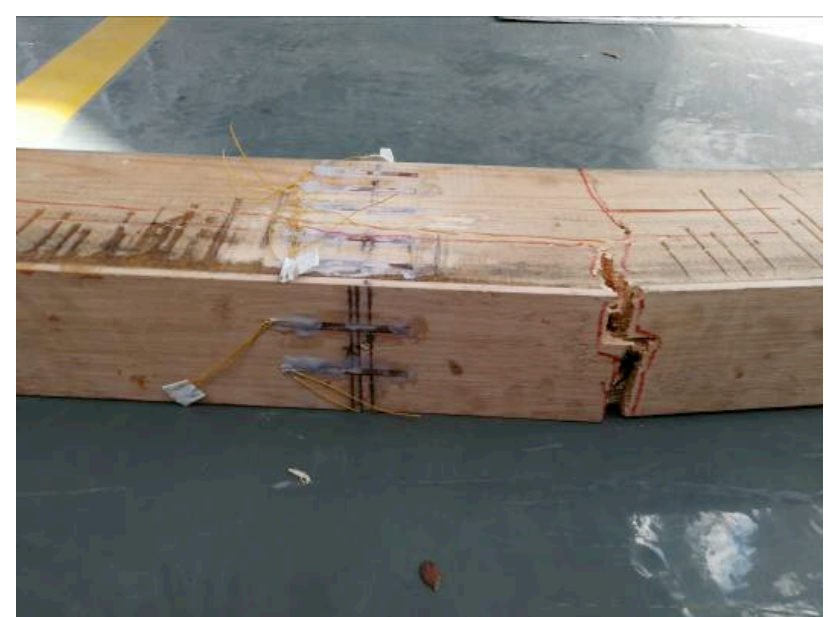

(b) Tensile failure of beam bottom

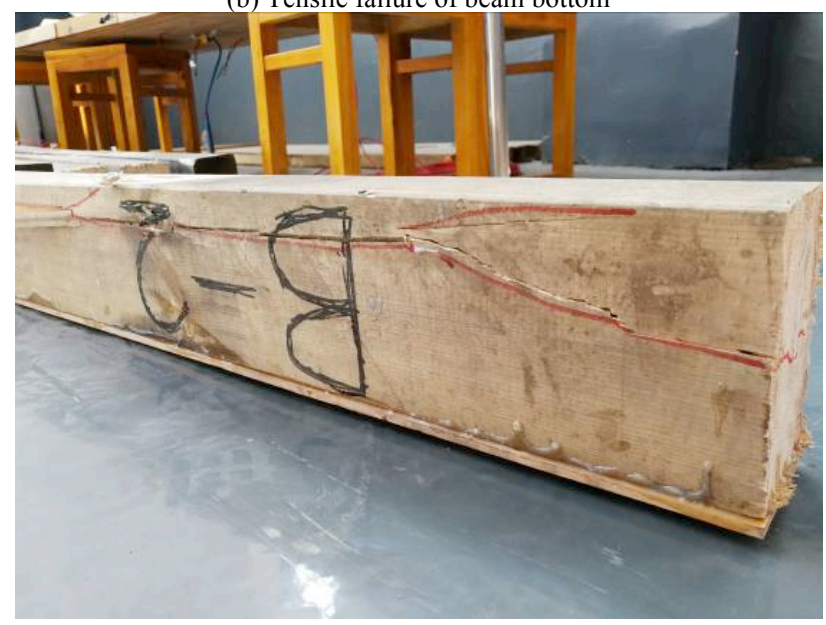

(c) Connected failure along the grain

Fig. 6. Typical failure modes of group B

\subsubsection{Main test results}

Major results of the flexural performance experiment are listed in Table 2, including the ultimate load $\left(P_{u}\right)$, midspan deflection $\left(\Delta_{u}\right)$, and flexural rigidity $(E I)$.

\subsection{Analysis of test results}

\subsubsection{Load-midspan deflection curve}

The midspan deflection of different specimens during the experiment was tested. The load-midspan deflection curve is shown in Fig. 7.

Table.2. Main test results

\begin{tabular}{c|c|c|c|c|c|c}
\hline No. & $P_{u} / k N$ & $\Delta_{u} / m m$ & $E I / N \cdot m^{2}$ & $\begin{array}{c}\text { Growth of } \\
P_{u} / \%\end{array}$ & $\begin{array}{c}\text { Growth of } \\
\Delta_{u} / \%\end{array}$ & $\begin{array}{c}\text { Growth of } \\
E I / \%\end{array}$ \\
\hline A1 & 23 & 23.7 & $120.4 \times 10^{9}$ & - & - & - \\
A3 & 32 & 33.6 & $127.2 \times 10^{9}$ & - & - & - \\
B1 & 47 & 43.9 & $169.3 \times 10^{9}$ & 75.6 & - & -1.3 \\
A2 & 40 & 39.8 & $131.5 \times 10^{9}$ & - & - & 49.4 \\
B2 & 50 & 39.3 & $196.5 \times 10^{9}$ & 25.0 & 12.6 & 34.9 \\
B3 & 47 & 44.8 & $177.4 \times 10^{9}$ & 17.5 & & \\
\hline
\end{tabular}

(Note: B1 is the mean between A1 and A3. Given that the deflection of B3 at failure is higher than $\mathrm{L} / 40,85 \%$ of the failure load was used as the ultimate load.) 


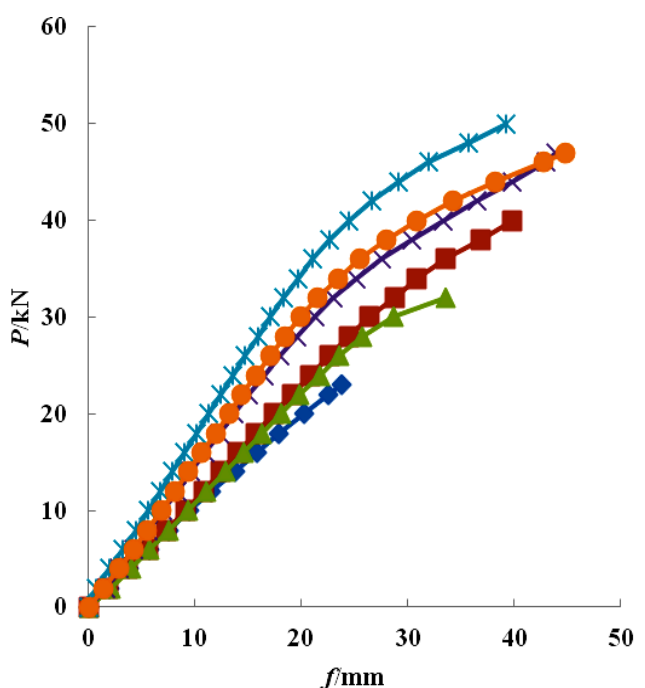

Fig. 7. Load-midspan deflection curve

Table 2 and Fig. 7 show that in the early stress period, the slopes of the load-deflection curve of bamboo-log composite beams were similar and presented linear changes, thus indicating the same rigidity. When the load gradually increased, the curve slope decreased, thereby indicating that the specimens entered the elastic-plastic stage. Compared with the log beam, the bamboo-log composite beams achieved a higher slope, thus indicating that the bamboo plate could increase specimen rigidity. The flexural capacity, rigidity, midspan deflection, and year-on-year growth of bamboo-log composite beams with evident knag in the tensile region increased by $75.6 \%, 36.9 \%, 58.2 \%$, and $17.4 \%$ compared with those of log beams. The flexural capacity, rigidity, midspan deflection and year-on-year growth of bamboo-log composite beams without evident knag in the tensile region increased by $17.5 \%-25 \%, 34.9 \%-49.4 \%$, $1.3 \%-12.6 \%$, and $4.9 \%-26.3 \%$ compared with those of $\log$ beams.

4.2.2 Strain variations of midspan section along the height

The plane cross-section assumption was verified by choosing typical specimens from A and B. Strain variations of midspan section along the specimen are shown in Fig.8.

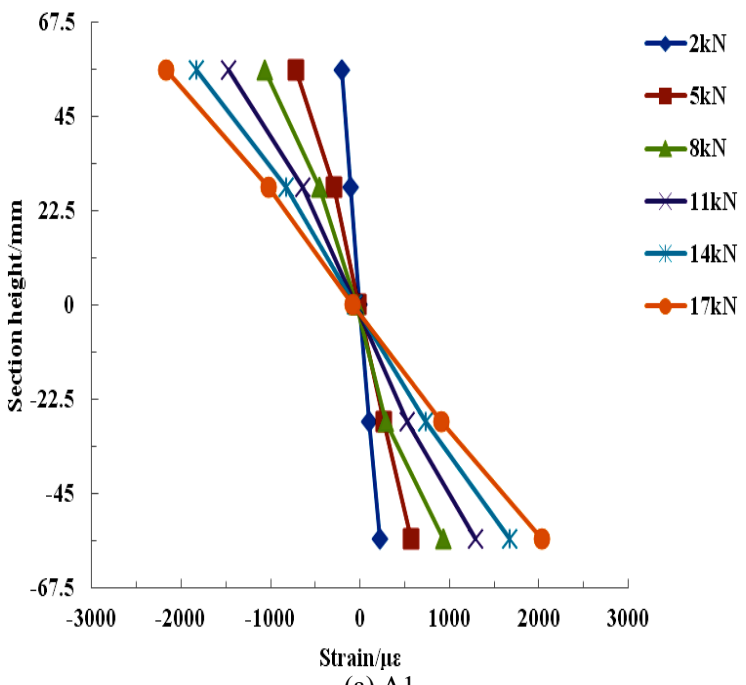

(a) A1

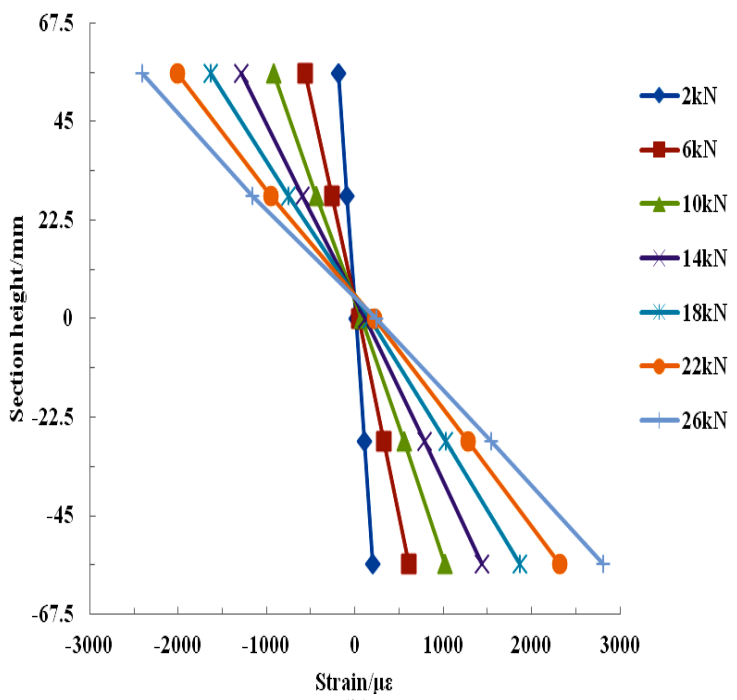

(b) A3

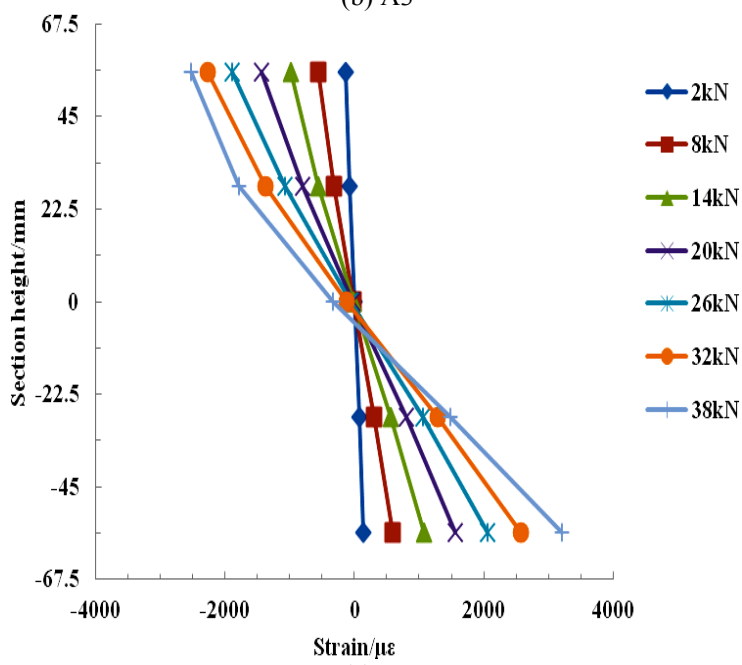

(c) B1

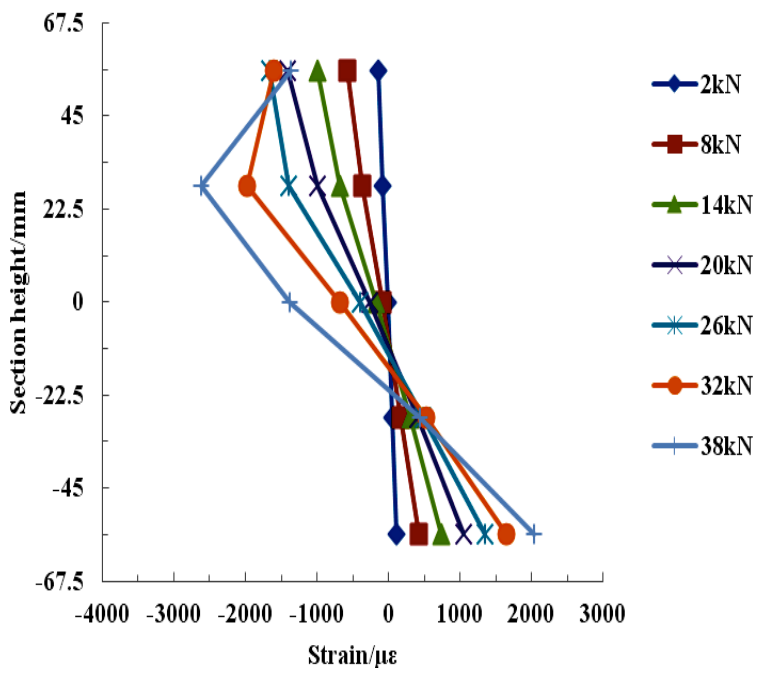

(d) B3

Fig. 8. Strain profile at mid-span cross-section

In Fig.8, midspan sectional strains of $\log$ beams and bamboo-log beams meet the plane cross-section assumption as loads increase. The neutral axis of bamboo-log composite beams moves downward slightly, accompanying by an expansion of compressive zone and bearing capacity. Given the load increases, the marginal compressive strain of the compressive zone decreases when it is close to the ultimate strain. This situation is caused by wrinkles in the compressive zone when the specimen enters the elastic- 
plastic stage. This result conforms to the deformation of the compressive zone upon crack development prior to specimen failure.

\subsubsection{Load-strain curve}

Top compressive strain and bottom tensile strain at different section positions of two groups are shown in Fig.9, where a is compressive strain and $b$ is tensile strain.

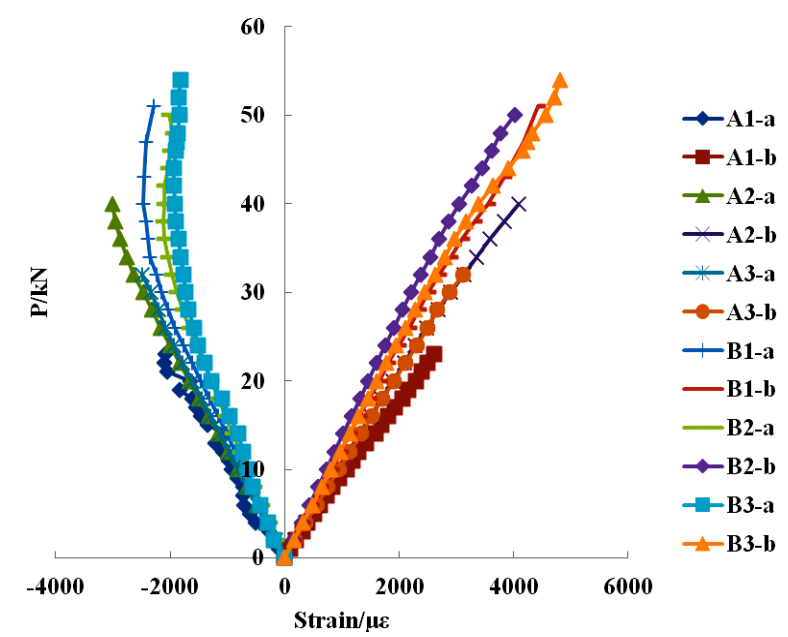

(a) $\mathrm{L} / 4$

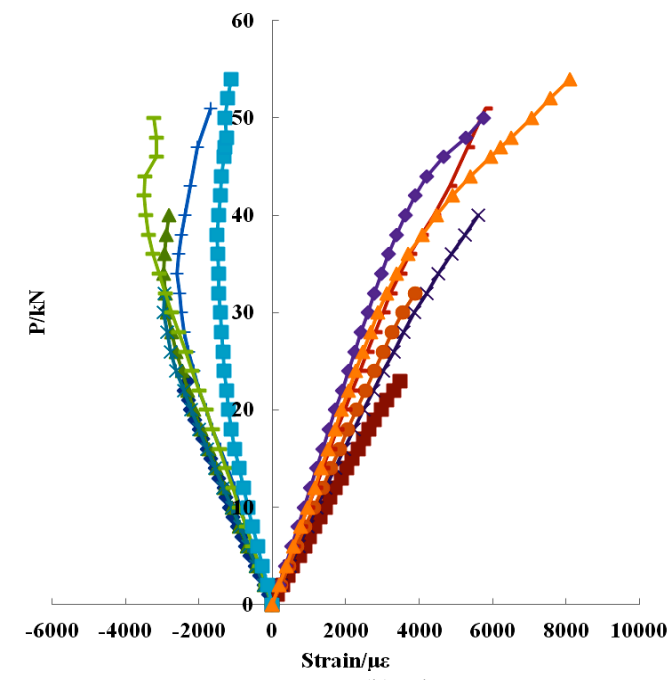

(b) $L / 2$

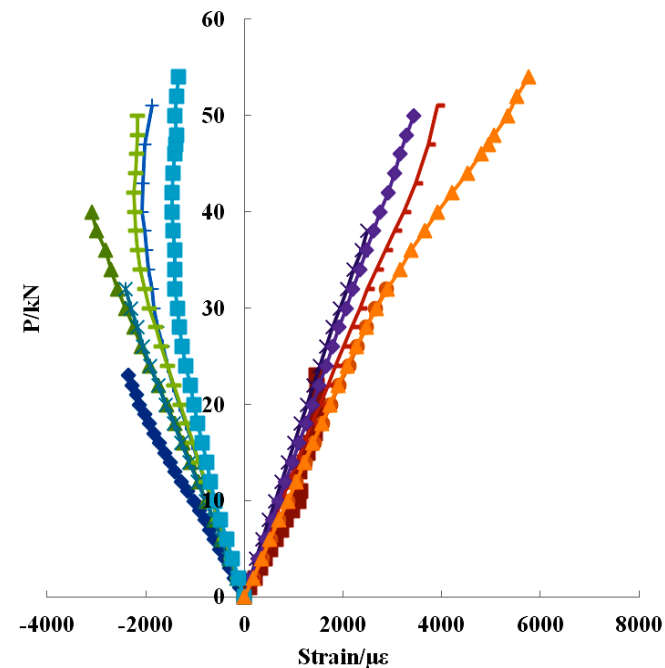

(c) $3 \mathrm{~L} / 4$

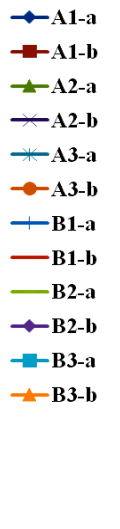

$-A 1-b$

$\triangle \mathrm{A} 2-\mathrm{a}$

$-\mathrm{A} 2-\mathrm{b}$
$-\mathrm{A} 3-\mathrm{a}$

$\rightarrow-\mathrm{A3}-\mathrm{b}$

+B1-a

B1-b

-B2-a

-B3-a

- B3-b

$\leadsto$ A1-a

- -A1-b

$-\mathrm{A} 2-\mathrm{a}$

$\leftarrow$ A2-b

* A3-a

$-\mathbf{A 3}$-b

-B1-a

-B1-b

-B2-a

$\leadsto$ B2-b

- B3-a

+ -B3-b

Fig. 9. Comparison of load versus strain profile

In Fig.9, compressive strain increases first and then decreases with load increase, which is caused by wrinkle cracking in the top compressive zone. The transverse force causes extrusion stress to result in strain rebounding. Compared with the log beam, the bamboo-log composite beams indicate the higher slope of the load-strain curve. The maximum positive stress of the transverse section of beam $\left(\sigma_{\max }\right)$ is:

$\sigma_{\max }=\frac{M}{W_{z}}$

where $M$ is the bending moment on the transverse section and $W_{z}$ is the bending sectional coefficient.

The bending section coefficient of the bamboo-log composite beam increased to a certain extent. Given the same loads, that is, a fixed bending moment of cross-section, the strain was slightly small, thus indicating that tensile properties of bamboo plate were used fully; this situation can strengthen the beam rigidity.

\subsubsection{Theoretical calculation of flexural capacity}

Tensile stress in the tensile region of bamboo-log composite beam was the collaborative effect of bamboo materials and timber materials. Owing to different elastic moduli of two materials, the method of sections was applied to verify the flexural ability of bamboo-log composite beams. In the calculation deduction process of flexural capacity, we presented the hypotheses below:

(1) After bending deformation of the bamboo-log composite beams, strain distribution along the section height conforms to the plane cross-section assumption.

(2) Bamboo and logs are ideal elastomers. The bondline thickness between the bamboo plate and the log is neglected. Two materials are bonded perfectly, without relative slippage.

The bearing capacity of composite beams is generally calculated by the mechanical property method of materials. The section of the composite beams was composed of bamboo materials and log materials were converted into the section of a single log material. Based on the principle of fixed positions of the resultant force acting point and value of the resultant force, the effective width of bamboo material ( $b$ ) can be converted into $b$ to maintain the fixed centroid position of the bamboo section:

$b^{\prime}=\frac{b}{\alpha_{E b}}$

where the coefficient $\alpha_{E b}$ is the ratio between elasticity modulus of $\log$ and elasticity modulus of bamboo.

The failure mode of specimens in the loading process is dominated by the tensile failure of bamboo sides, and the compressive strain of $\log$ at the beam top is smaller than the ultimate compressive strain. The simplified calculation diagram of the bamboo-log composite beams is shown in Fig. 10. 


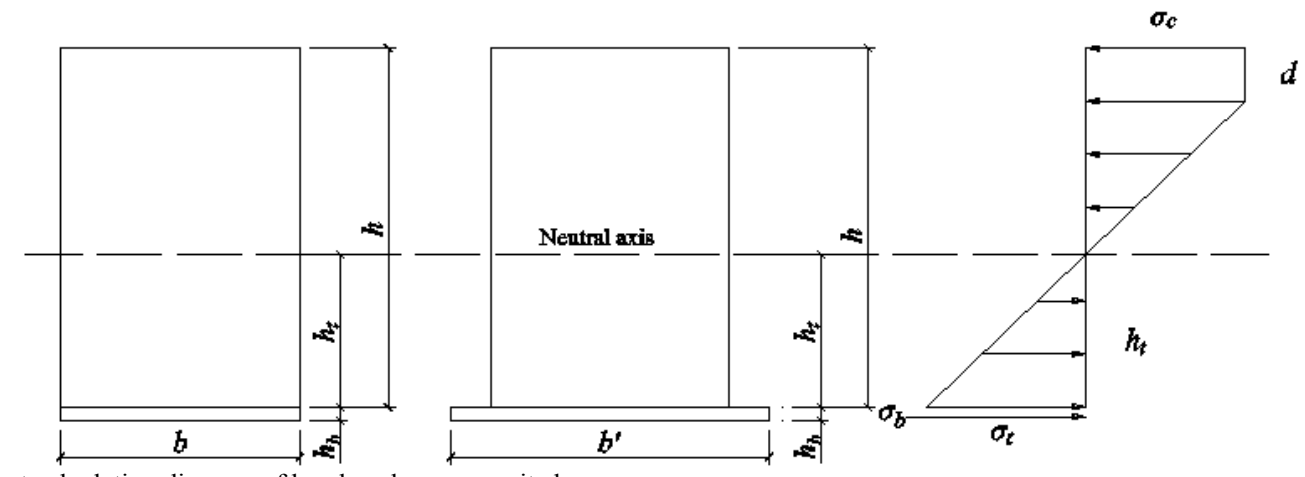

Fig. 10. Equivalent calculation diagram of bamboo-log composite beam

The equilibrium conditions between internal force and moment of force indicate that:

$$
\begin{aligned}
& \sigma_{c} d b+\frac{1}{2} \sigma_{c} \times\left(h-h_{t}-d\right) \times b=\sigma_{b} h_{b} b^{\prime}+\frac{1}{2} h_{t} \sigma_{t} b \\
& M_{u}=\sigma_{c} d b \times\left(h-\frac{d}{2}\right)+\frac{1}{2} \sigma_{c} \times b \times\left[\frac{2}{3}\left(h-h_{t}-d\right)+h_{t}\right] \times\left(h-h_{t}-d\right)-\frac{1}{6} \sigma_{t} b h_{t}^{2}
\end{aligned}
$$

where $h$ is the section height of the $\log$ beam, $h_{t}$ is the height of the tensile region of log beam, $h_{b}$ is the thickness of bamboo plate, $b$ is the section width of beams, $b$ is the converted section width, $\sigma_{c}$ is the compressive stress at $\log$ top, $\sigma_{t}$ is the tensile stress at log bottom, $\sigma_{b}$ is the tensile stress of bamboo plate, $d$ is the plastic development height of beam section, and $M_{u}$ is the designed section bending moment of the bamboo-log composite beam.

Based on the measurement of material parameters [23], the bending moment of midspan section was calculated based on Eq.(4). Calculated results were compared with test results (Table 3 ).

Table.3. Comparison of theory value and test value of bending capacity

\begin{tabular}{c|c|c|c|c}
\hline No. & $h_{t} / \mathrm{mm}$ & Calculated results $/ k N \cdot m$ & Test results $/ k N \cdot m$ & Error/\% \\
\hline B1 & 47.40 & 14.21 & 13.95 & -1.83 \\
B2 & 54.98 & 12.62 & 14.88 & 17.91 \\
B3 & 42.33 & 12.97 & 13.64 & 5.17 \\
Mean & - & - & - & 7.08 \\
\hline
\end{tabular}

Table 3 shows that the calculated flexural capacity of bamboo-log composite beam indicates an error of less than $20 \%$ with test results. The average error is controlled lower than $10 \%$. Therefore, the proposed calculation formula of flexural capacity is reasonable and feasible.

\section{Conclusion}

To solve the poor bearing capacity of traditional timber structures and increase utilization of bamboo materials and timber materials, a new bamboo-log composite beam was designed. The flexural capacities of three log beams and three bamboo-log composite beams were compared. The load-deflection characteristics and strain variations on midspan section along the height and load-strain relationship of the composite beams were analyzed. The below conclusions are drawn.

(1) The brittle failure is the major failure mode of bamboo-log composite beam in the bending experiment. The bottom tensile failure is the major failure mode. Fractures mainly begin to extend from the defection of timber material at failure. Knag of the tensile region can significantly influence the flexural capacity.

(2) The flexural capacity and rigidity of bamboo-log composite beam are $17.5 \%-75.6 \%$ and $34.9 \%-49.4 \%$ higher than those of log beams, thereby showing an average growth of $39.4 \%$ and $42.2 \%$, respectively. The midspan ultimate deflection is increased by $-1.3 \%-58.2 \%$ and 23.2 on average. These values indicate that bamboo-log composite beams are superior to log beams in mechanical properties.

(3) Bamboo and timber materials can cooperate without relative slippage. The neutral axis of bamboo-log composite beams is slightly lower than that of control specimens. Given the same loads, the tensile strain and compressive strain of bamboo-log composite beams are smaller than those of $\log$ beams. Strain variations of specimen sections along the height conform to the plane cross-section assumption.

(4) The calculation formula of flexural capacity of bamboo-log composite beams is proposed. Calculated results and test results are compared. Results demonstrated that the average error is lower than $10 \%$.

The proposed bamboo-log composite beam applies original ecological green materials and shows high mechanical properties as well as high-cost performance. The beam uses assembly construction. Using the bamboo-log composite beams in projects can decrease energy consumption and project cost. Use of the beams can provide theoretical and test support to the application of timber structures. Owing to the small sample size, further studies on other influencing factors are needed. 


\section{Acknowledgements}

This work was supported by the International S\&T

Cooperation Program of China (Grant No. 2014DFA53120).
This is an Open Access article distributed under the terms of the Creative Commons Attribution License

\section{References}

1. XU Ji-de, "The 8th Forest Resources Inventory Results and Analysis in China". Forestry Economics, 36(3), 2014, pp.6-8.(in Chinese)

2. Camille A. Issa, Ziad Kmeid, "Advanced wood engineering: glulam beams". Construction and Building Materials, 19(2), 2004, pp. 99106.

3. Peggi Clouston, Leander A. Bathon, Alexander Schreyer, "Shear and Bending Performance of a Novel Wood-Concrete Composite System". Journal of Structural Engineering, 131(9), 2005, pp.1404-1412.

4. Prof. Dr. Eng. Masanori Fujita, Junpei Sakai, Hirotaka Oda,et al., "Building system for a composite steel-timber structure". Steel Construction, 7(3), 2014, pp.183-187.

5. HU Xia-min, LI Qiao, PENG Hong-yi, et al., "Experimental study on wood-concrete composite beams". Journal of Building Structures, 34(S1), 2013, pp.371-376. (in Chinese)

6. CHEN Chun, HU Xia-min, WEI Chen-yu, "Experimental study on glulam-concrete composite beams strengthened with carbon fiber reinforced composite". Journal of Nanjing Tech University(Natural Science Edition), 37(6), 2015, pp.75-80. (in Chinese)

7. Ewa Szumigala, Maciej Szumigala, Lukasz Polus, "A Numerical Analysis of the Resistance and Stiffness of the Timber and Concrete Composite Beam". Civil And Environmental Engineering Reports, 15(4),2015, pp.139-150.

8. J.Balogh, M.Fragiacom, R.M.Gutkowski, et al., "Influence of Repeated and Sustained Loading on the Performance of Layered Wood-Concrete Composite Beams". Journal of Structural Engineering, 134(3) 2008, pp. 430-439.

9. Lorenzo Boccadoro, Simon Zweidler, Rene Steiger, et al., "Calculation Model to Assess the Structural Behavior of LVLConcrete Composite Members with Ductile Notched Connection". Engineering Structures, 153(15),2017, pp.106-117.

10. CHEN Ai-guo, LI Deng-hui, FANG Chao, et al., "Experimental study on flexural behavior of $\mathrm{H}$-shaped steel-wood composite beams". Journal of Building Structures, 37(S1), 2016, pp. 261-267. (in Chinese)

11. SUN Hong-ye, BAI Li-bin, LI Deng-hui, "Numerical simulation and parameter analysis of flexural behavior of $\mathrm{H}$-shape steel-wood composite beams". Building Structure, 47(13), 2017, pp. 51-56. (in Chinese)

12. Daniel P.Hindman, Joseph R.Loferski, "Cold-Formed Steel Reinforcement for Improperly Cut Wood Composite IJoists". Practice Periodical on Structural Design and Construction,13(4), 2008, pp.198-203.
13. Julio Soriano, Bruno Piva Pellis, Nilson Tadeu Mascia, "Mechanical performance of glued-laminated timber beams symmetrically reinforced with steel bars". Composite Structures, 150, 2016, pp.200-207.

14. Cristiano Loss, Maurizio Piazza, Riccardo Zandonini, "Connections for steel-timber hybrid prefabricated buildings. Part II: Innovative modular structures". Construction and Building Materials, 122, 2016, pp.769-808.

15. Zheng Li, Minjuan He, Xijun Wang, et al., "Seismic performance assessment of steel frame infilled with prefabricated wood shear walls". Journal of Constructional Steel Research, 140, 2018, pp.6273.

16. M. Khelifa,A. Celzard,M. Oudjene,et al., "Experimental and numerical analysis of CFRP-strengthened finger-jointed timber beams". International Journal of Adhesion and Adhesives, 68, 2016, pp.283-297.

17. XIONG Hai-bei, KANG Jia-hua, LV Xi-lin, "Bending tests investigation on composite timber beam". Journal of Tongji University(Natural Science), 40(4), 2012, pp.522-528. (in Chinese)

18. J. Estévez-Cimadevila, F. Suárez-Riestra, D. Otero-Chans,et al., "Experimental Analysis of Pretensioned CLT-Glulam T-Section Beams". Advances in Materials Science and Engineering, 2018(12), 2018, pp.1-12.

19. Y. Xiao,Y. Wu, J. Li, et al., "An experimental study on shear strength of glubam". Construction and Building Materials, 150, 2017, pp.490-500.

20. CHEN Guo, ZHANG Qi-sheng, HUANG Dong-sheng, et al., "Bending Test of OSB webbed bamboo I-Joist". Journal of Hunan University(Natural Sciences), 42 (5), 2015, pp.72-79. (in Chinese)

21. CHEN Guo, ZHOU Tao, LI Cheng-long, "Experimental study on the OSB webbed bamboo beams". Journal of Nanjing Forestry University(Natural Sciences Edition), 40(5), 2016, pp.121-125. (in Chinese)

22. Viviana Paniagua, Roger Moya, "Flexural Performance of I-Joists Fabricated with Glue-Laminated Bamboo and Gmelina Arborea Plywood". Open Journal of Civil Engineering, 4(3), 2014, pp.209216.

23. Zhang Ye-tian, HE Li-ping, "Comparison of mechanical properties for glued laminated bamboo wood and common structural timbers". Journal of Zhejiang Forestry College, 24(1), 2007, pp.100-104. (in Chinese). 